\title{
Continuous Measurements of Bubble Characteristics in a Molten Iron Bath with Ar Gas Injection
}

\author{
Manabu IGUCHI, Hirotoshi KAWABATA, Yoichi ITO, () Keiji NAKAJIMA ${ }^{2)}$ and Zen-ichiro MORITA ${ }^{3)}$ \\ Faculty of Engineering, Osaka University, Yamadaoka, Suita, Osaka-fu, 565 Japan. \\ 1) Formerly Graduate Student, Osaka \\ University. Now at Kawasaki Steel Corp., Kawasaki-dori, Mizushima, Kurashiki, Okayama-ken, 712 Japan. \\ 2) Sumitomo \\ Metal Industries, Ltd., Fuso-cho, Amagasaki, Hyogo-ken, 660 Japan. \\ Sumitomo Metal Industries, Ltd., Fuso-cho, Amagasaki, Hyogo-ken, 660 Japan.
}

(Received on June 2, 1994; accepted in final form on September 16, 1994)

\begin{abstract}
Present authours developed a new electro-resistivity probe being able to continuously measure bubble characteristics in a molten iron bath agitated by gas injection. The life of the probe was about two hours at a bath temperature of $1250^{\circ} \mathrm{C}$. The axial and radial distributions of gas holdup $\alpha$, bubble frequency $f_{B}$, mean bubble rising velocity $\bar{u}_{B}$ and mean bubble diameter $\bar{d}_{B}$ were determined for the Ar gas flow rates of 50 and $100 \mathrm{~cm}^{3} / \mathrm{s}$ (at $1250^{\circ} \mathrm{C}$ ). The Ar gas was preheated up to $1250^{\circ} \mathrm{C}$ and then injected through a single-hole centric bottom nozzle.

The results were compared with empirical correlations derived from cold and hot model experiments. The measured values of $\alpha, f_{B}$ and $\bar{u}_{B}$ in the upper part of the bath were approximated satisfactorily by correlations proposed by the present authors, but they did not agree with the experimental results of Kawakami et al. The measured values of $\bar{d}_{B}$ were a little smaller than predicted values by Sano et al. and Irons et al.
\end{abstract}

KEY WORDS: electro-resistivity probe; molten iron; bubbling jet; steelmaking; injection; gas holdup; bubble frequency; bubble rising velocity; bubble diameter.

\section{Introduction}

Recent extensive utilization of gas injection techniques promoted the fundamental research on bubble and liquid flow characteristics in molten metal baths. In the initial stage the so-called cold model experiments using water, mercury and molten Wood's metal baths were actively carried out to clarify the bubble and liquid flow characteristics and the mixing time ${ }^{1-5}$ because these liquid materials are easy to handle. Empirical correlations of the bubble characteristics (gas holdup $\alpha$, bubble frequency $f_{B}$, mean bubble rising velocity $\bar{u}_{B}$ and mean bubble diameter $\bar{d}_{B}$ ) of bubbling jet formed in a bath by gas injection have been proposed by many researchers including the present authors. However, the applicability of these correlations to the bubble characteristics in high temperature molten metal baths has hardly been studied.

In the second stage some experiments were performed on the bubble formation in high temperature molten metal baths. ${ }^{6-9)}$ Sano et al..$^{6,7)}$ measured the bubble frequency generated at a single-hole nozzle exit in a molten silver bath at $1000^{\circ} \mathrm{C}$ and in a molten iron bath at $1600^{\circ} \mathrm{C}$ using a pressure sensor technique. Irons and Guthrie $^{8)}$ employed a similar acoustic device and observed the Ar bubble formation at some kinds of nozzles immersed in a molten iron bath at $1250^{\circ} \mathrm{C}$. However, these researchers did not mention the characteristics of rising bubbles in the bath.
Recently, Kawakami et al. ${ }^{93}$ measured the gas holdup, bubble frequency, mean bubble rising velocity, and mean bubble diameter in a molten iron and a molten copper bath at $1250^{\circ} \mathrm{C}$ with a two-needle electro-resistivity probe. They used a carbon wire as the electrode needle of the probe. The life of the electrode needle was less than $3 \mathrm{~min}$ due to the serious erosion of the electrode needle. It was therefore difficult to measure the bubble characteristics continuously and systematically by using that probe.

The present authors have developed a new electroresistivity probe being able to continuously measure the bubble characteristics in high temperature molten metal baths. The life of this probe was about $2 \mathrm{~h}$ in a molten iron bath at $1250^{\circ} \mathrm{C}$. Using this probe, the axial and radial distributions of gas holdup $\alpha$, bubble frequency $f_{B}$, mean bubble rising velocity $\bar{u}_{B}$ and mean bubble diameter $\bar{d}_{B}$ in a molten iron bath at $1250^{\circ} \mathrm{C}$ were systematically measured. The bath was agitated by Ar gas injection through a centric bottom nozzle. The experimental results were compared with empirical correlations derived from cold model experiments.

\section{Some Aspects of a New Two-needle Electro-resistivity Probe}

Materials with high resistivity against erosion and chemical reactions in a molten iron bath at high 


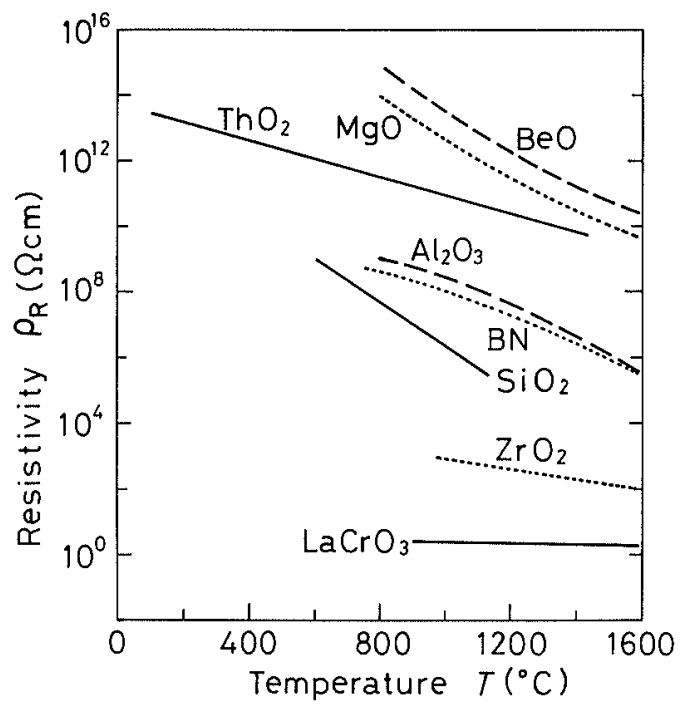

Fig. 1. Resistivity for various refractory materials at high temperature.

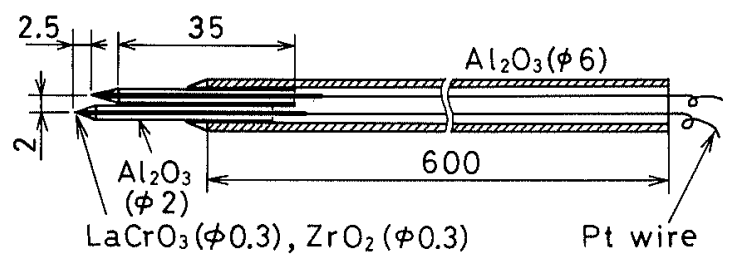

Fig. 2. Electro-resistivity probe for measuring bubbles in molten iron bath.

temperatures must be chosen as the electrode needle. Mechanical strength also is one of important properties required for the insulator.

The resistivity of some candidate materials at high temperatures ${ }^{10-12)}$ are plotted in Fig. 1. A schematic view of a new two-needle electro-resistivity probe is shown in Fig. 2. The electrode needle of the electroresistivity probe was made of a $\mathrm{LaCrO}_{3}$ wire or a $\mathrm{ZrO}_{2}$ wire because the erosion resistivity of these materials was very high and the electric resistance was relatively low as shown in Fig. 1. $\mathrm{Al}_{2} \mathrm{O}_{3}$ was used as the insulator. The vertical separation $L_{p}$ between the lower and upper electrode needles was set at $2.5 \mathrm{~mm}$. We were able to accurately measure the bubble characteristics in a molten iron bath at $1250^{\circ} \mathrm{C}$ over $2 \mathrm{~h}$ using this electro-resistivity probe.

\section{Experimental Apparatus and Procedure}

Figure 3 shows a schematic view of the experimental apparatus. The carbon crucible having an inner diameter $D$ of $90 \mathrm{~mm}$ and a height of $180 \mathrm{~mm}$ was placed in a Tamman furnace, and pig iron was melted in it. The bath depth was set at $120 \mathrm{~mm}$ and the bath temperature measured with a thermocouple was kept at $1250^{\circ} \mathrm{C}$. The components of molten iron are $\mathrm{Fe}: 95.1 \mathrm{wt} \%, \mathrm{C}$ : $4.48 w \mathrm{t} \%$, Si: $0.10 \mathrm{wt} \%$, Mn: $0.20 \mathrm{wt} \%$, P: $0.11 \mathrm{wt} \%$ and $\mathrm{S}: 0.001 \mathrm{wt} \%$. Ar gas was injected into the bath through a centric single-hole bottom nozzle made of alumina at gas flow rates of $50 \mathrm{~cm}^{3} / \mathrm{s}$ and of $100 \mathrm{~cm}^{3} / \mathrm{s}$. The inner and outer diameters of the nozzle were $1 \mathrm{~mm}$ and $6 \mathrm{~mm}$, respectively (see Fig. 4). The gas flow rate was evaluated

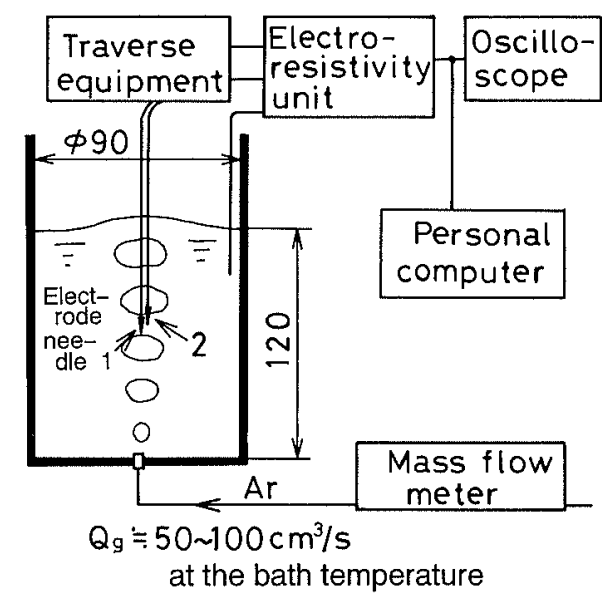

Fig. 3. Experimental apparatus for measuring bubbles in molten iron bath.

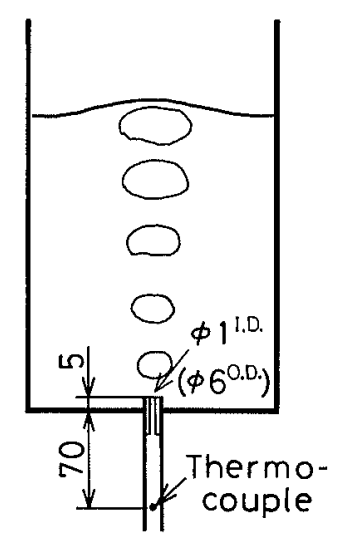

Fig. 4. Shape of bottom blowing nozzle and measurement position of Ar gas temperature.

at $1250^{\circ} \mathrm{C}$ and $101 \mathrm{kPa}$. The Ar gas flow rate was adjusted by using a mass flow meter. The origin of the coordinate system was placed at the center of the nozzle exit. The axial and radial coordinates were represented by $z$ and $r$, respectively.

The temperatures of Ar gas measured using a thermocouple at $75 \mathrm{~mm}$ upstream from the nozzle exit were 910 and $870^{\circ} \mathrm{C}$ for the gas flow rates of 50 and $100 \mathrm{~cm}^{3} / \mathrm{s}$, respectively. According to heat transfer calculation, the gas temperature was estimated to be approximately $1250^{\circ} \mathrm{C}$ at $10 \mathrm{~mm}$ upstream from the nozzle exit. Accordingly it was not necessary to consider the gas expansion due to a temperature difference.

The electro-resistivity probe was attached to traverse equipment, preheated above the bath surface for more than $20 \mathrm{~min}$ and then gradually immersed into the molten iron bath in order to avoid heat shock.

The output signals of the two-needle electro-resistivity probe system were $A / D$ converted at a sampling frequency of $2 \mathrm{kHz}$ and subsequently processed on a personal computer. The wave forms of the signals were monitored with an oscilloscope during the measurements. A typical example of the wave forms is shown in Fig. 5. By adjusting the resistance of the electric circuit of the electro-resistivity probe system, the output voltage was set at $2 \mathrm{~V}$ when the electrode was surrounded by molten iron and at $0.5 \mathrm{~V}$ when the electrode was surrounded by 


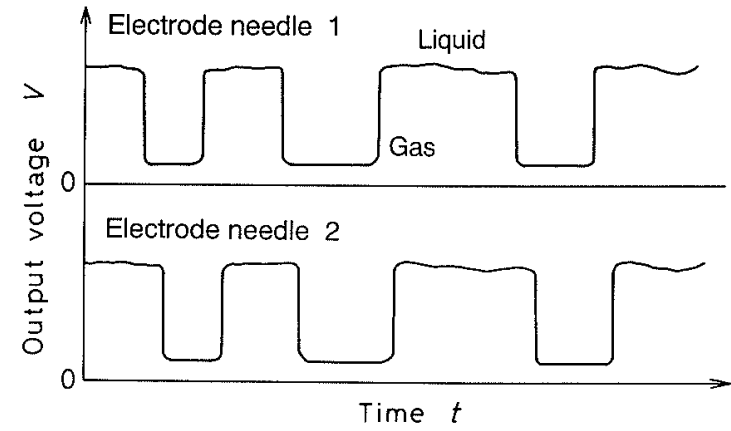

Fig. 5. Sketch of the output voltage of the probe using $\mathrm{LaCrO}_{3}$ electrode at $1250^{\circ} \mathrm{C}$.

Ar gas. The output voltage for liquid phase fluctuated with an amplitude of $0.05 \mathrm{~V}$ and a period of about $30 \mathrm{~min}$ due to the fluctuation of the voltage of the electric furnace. Whenever the deviation of the output voltage exceeded $0.1 \mathrm{~V}$, the resistance of the system was adjusted so that the output voltage become $2 \mathrm{~V}$ again. The measurements were stopped when the adjustment of resistance became impossible.

Measurements on the bath centerline were continued until the number of reliable bubble rising velocity data exceeded 30 . The measurement was repeated 5-10 times at each measurement position and the average value was determined. On the other hand, the measurement time at each radial position was set at $4 \mathrm{sec}$.

In the case of measuring the mean bubble rising velocity $\bar{u}_{B}$ and mean bubble diameter $\bar{d}_{B}$, when the bubble residence time at the tip of the upper electrode 2 was between 0.7 and 1.3 times as large as that at the tip of the lower electrode 1 , these signals were treated as output signals from the same bubble. The bubble rising velocity $\bar{u}_{B}$ was obtained from $L_{p} / \Delta t$, where $L_{p}$ is the vertical separation of the two electrode needles and $\Delta t$ is delay time between the two electrode tips. Gas holdup $\alpha$ was defined as the ratio of the summation of bubble residence time at the tip of the electrode 1 to total measurement time. Bubble frequency $f_{B}$ was the number of bubbles passing through the tip of the electrode 1 in one second. The mean bubble diameter $\bar{d}_{B}$ was defined by $\bar{d}_{B}=1.5 \bar{L}_{B}$, where $\bar{L}_{B}$ was the mean chord length of a bubble and the bubble was assumed to have a spherical shape. ${ }^{9)}$

\section{Experimental Results and Discussion}

\subsection{Axial Distributions of Bubble Characteristics}

Figure 6 shows the gas holdup on the centerline of the bath, $\alpha_{\mathrm{cl}}$, for the Ar gas flow rates of $Q_{g}=50 \mathrm{~cm}^{3} / \mathrm{s}$ and $Q_{g}=100 \mathrm{~cm}^{3} / \mathrm{s}$, where $z$ is the vertical distance from the nozzle exit. It should be noted that at each measurement position in Fig. 6 the measured values for $Q_{g}=50 \mathrm{~cm}^{3} / \mathrm{s}$ (O) and $Q_{g}=100 \mathrm{~cm}^{3} / \mathrm{s}(\bullet)$ are slightly shifted to the left and right, respectively, in order to avoid overlapping. The scatter of data around the mean value is represented by an error bar.

The measured values of $\alpha_{c 1}$ decreased monotonously from approximately $60 \%$ near the nozzle exit $(z=15 \mathrm{~mm})$ to about $20 \%$ near the bath surface $(z=75 \mathrm{~mm})$. The

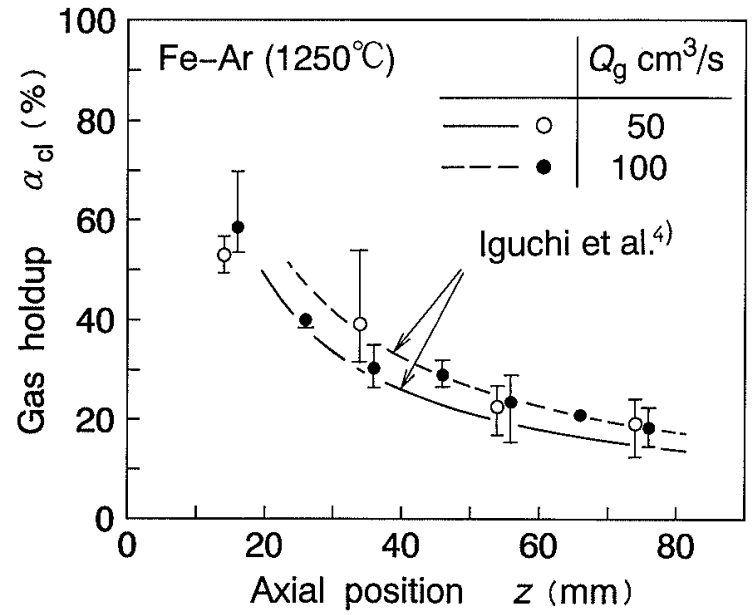

Fig. 6. Axial distributions of gas holdup $\alpha_{c l}$ on the bath centerline in the molten iron bath with bottom blowing $\left(1250^{\circ} \mathrm{C}\right.$ ). (Plots $(\mathrm{O}, \mathrm{)})$ were slightly shifted to the left and right to avoid overlapping.)

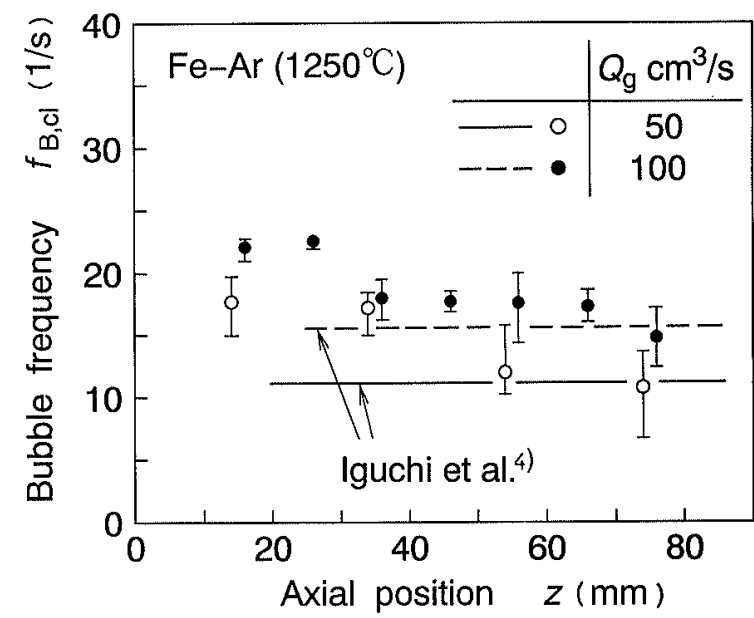

Fig. 7. Axial distributions of bubble frequency $f_{B, c l}$ on the bath centerline in the molten iron bath with bottom blowing $\left(1250^{\circ} \mathrm{C}\right)$. (Plots $(\mathrm{O}, 0)$ were slightly shifted to the left and right to avoid overlapping.)

solid line for $Q_{g}=50 \mathrm{~cm}^{3} / \mathrm{s}$, which is valid for $z \geqq 19.6 \mathrm{~mm}$, and the broken line for $Q_{g}=100 \mathrm{~cm}^{3} / \mathrm{s}$, which is valid for $z \geqq 25.0 \mathrm{~mm}$, in the Figure were calculated from an empirical correlation derived by the present authors ${ }^{4)}$ for the ratio of liquid density to gas density $\rho_{L} / \rho_{g}$ from 800 to 12000 and for $\alpha_{c l}=10-50 \%$. Under the present experimental conditions the density ratio $\rho_{L} / \rho_{g}$ was approximately 21000 . Nevertheless, agreement between the present measured values in the molten iron bath and the empirical correlation for cold model was relatively good for each Ar gas flow rate.

Figure 7 plots the bubble frequency on the centerline of the bath $f_{B, c l}$. As the gas flow rate increased from 50 to $100 \mathrm{~cm}^{3} / \mathrm{s}, f_{B, c l}$ also increased at every axial position. The measured values for each gas flow rate were larger than the predicted values in the region near the nozzle exit and agreed very well with them in the region near the bath surface.

Figure 8 shows the mean bubble rising velocity on the bath centerline $\bar{u}_{B, c l}$. At $z=15 \mathrm{~mm}$, the measured values of $\bar{u}_{B, c l}$ for the two gas flow rates agreed well with each 


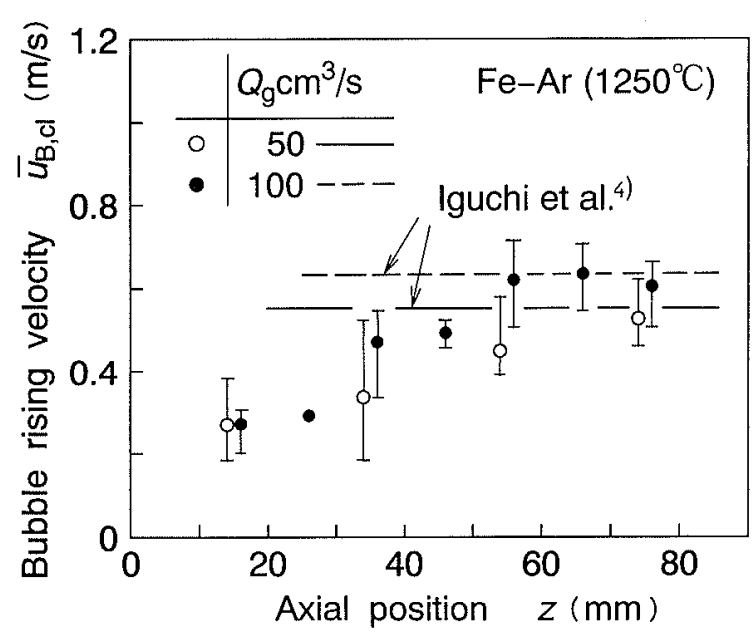

Fig. 8. Axial distributions of mean bubble rising velocity $\bar{u}_{B, c l}$ on the bath centrerline in the molten iron bath with bottom blowing $\left(1250^{\circ} \mathrm{C}\right)$. (Plots $(\mathrm{O}, 0)$ were slightly shifted to the left and right to avoid overlapping.)

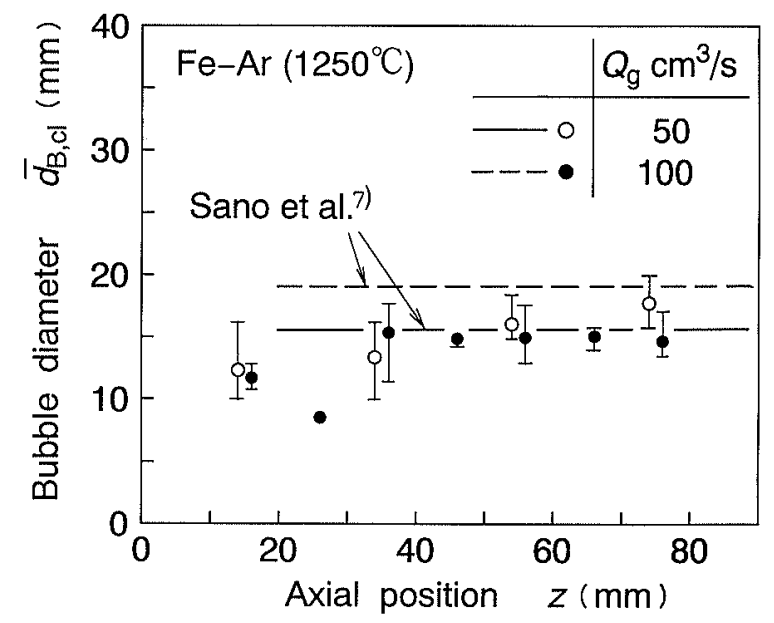

Fig. 9. Axial distributions of mean bubble diameter $\vec{d}_{B, c l}$ on the bath centerline in the molten iron bath with bottom blowing $\left(1250^{\circ} \mathrm{C}\right.$ ). (Plots $(\mathrm{O}, \mathrm{O})$ were slightly shifted to the left and right to avoid overlapping.)

other. As $z$ increased, $\bar{u}_{B, c l}$ increased and approached $0.54 \mathrm{~m} / \mathrm{s}$ for $Q_{g}=50 \mathrm{~cm}^{3} / \mathrm{s}$ and $0.64 \mathrm{~m} / \mathrm{s}$ for $Q_{g}=100 \mathrm{~cm}^{3} / \mathrm{s}$ in the axial region of $z \geqq 55 \mathrm{~mm}$. Agreement between the measured values and the empirical correlation was relatively good in the region near the bath surface.

Figure 9 shows the axial distributions of mean bubble diameter on the bath centerline $\bar{d}_{B, c l}$. The measured values of $\bar{d}_{B, c l}$ exhibited almost the same value of $12 \mathrm{~mm}$ in the region near the nozzle exit for the two gas flow rates, gradually increased as $z$ increased and became approximately $15 \mathrm{~mm}$ in the axial region of $z \geqq 35 \mathrm{~mm}$. Since the diameter of rising bubbles is approximately $15 \mathrm{~mm}$, the axial position of $z=15 \mathrm{~mm}$ is located in the upper end of the bubble formation region. Therefore the mean bubble rising velocity measured at $z=15 \mathrm{~mm}$ does not represent the real rising velocity but the expanding velocity of a bubble on the nozzle exit. Also, the mean bubble diamter obtained at $z=15 \mathrm{~mm}$ does not represent the real mean bubble diameter.

It is widely accepted that the wettability between the nozzle material and molten metal plays an important

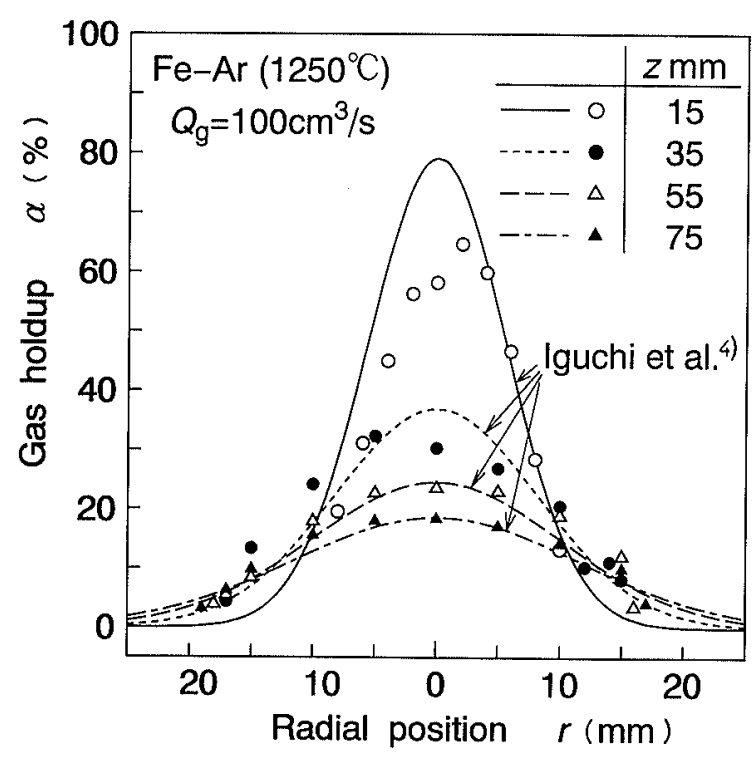

Fig. 10. Radial profiles of gas holdup $\alpha$ at different axial positions in the molten iron bath with bottom blowing (1 $\left.250^{\circ} \mathrm{C}\right)$.

role for the bubble formation. Sano et al. ${ }^{7)}$ measured the mean bubble diameter $\bar{d}_{B}$ at the nozzle exit in the molten silver bath at $1000^{\circ} \mathrm{C}$ and the molten iron bath at $1600^{\circ} \mathrm{C}$ and proposed the following empirical correlation for the case of bad wettability by referring to empirical correlation derived by Davidson and Amick $^{1)}$ for a waterair system.

$$
\bar{d}_{B}=\left[\left\{6 \sigma d_{n o} /\left(\rho_{L} g\right)\right\}^{2}+\left\{0.54\left(Q_{g} d_{n o}^{0.5}\right)^{0.289}\right\}^{6}\right]^{1 / 6}
$$

where $\sigma$ is the surface tension, $d_{n o}$ the outer diameter of the nozzle, $g$ the acceleration due to gravity.

Equation (1) yielded $\bar{d}_{B}=15.5 \mathrm{~mm}$ for $Q_{g}=50 \mathrm{~cm}^{3} / \mathrm{s}$ and $\bar{d}_{B}=19 \mathrm{~mm}$ for $Q_{g}=100 \mathrm{~cm}^{3} / \mathrm{s}$, as shown in Fig. 9 . In the case of $Q_{g}=50 \mathrm{~cm}^{3} / \mathrm{s}, \mathrm{Eq}$. (1) was able to satisfactorily predict the present measured values, but in the case of $Q_{g}=100 \mathrm{~cm}^{3} / \mathrm{s}$, Eq. (1) overestimated present mean bubble diameter. Such discrepancy might be attributable to the difference in the measuring method. In this study the mean bubble diameter $\bar{d}_{B}$ was determined by multiplying the mean chord length by 1.5 . Contribution of small bubbles, which were generated owing to disintegration of large bubbles coming from the nozzle exit, to the mean chord length was considered in this analysis. Meanwhile, Sane et al. evaluated the mean bubble diameter $\bar{d}_{B}$ at the nozzle exit using an acoustic method, and consequently, the contribution of small bubbles to $\bar{d}_{B}$ was not mentioned.

Irons et $a l .^{8)}$ also measured $\bar{d}_{B}$ in a molten iron bath at $1250^{\circ} \mathrm{C}$ using the same measuring method as Sano et al. Measured values of $\bar{d}_{B}$ for a nozzle with an outer diameter of $6.35 \mathrm{~mm}$, being almost the same as the outer diameter of $6.0 \mathrm{~mm}$ employed in this study, fell between about 15 and $22 \mathrm{~mm}$. These measured values were apparently larger than the present measured values. This discrepancy also might be caused by the difference in the measuring method.

\subsection{Radial Distributions of Bubble Characteristics}

Figure 10 shows the radial distributions of gas hold 


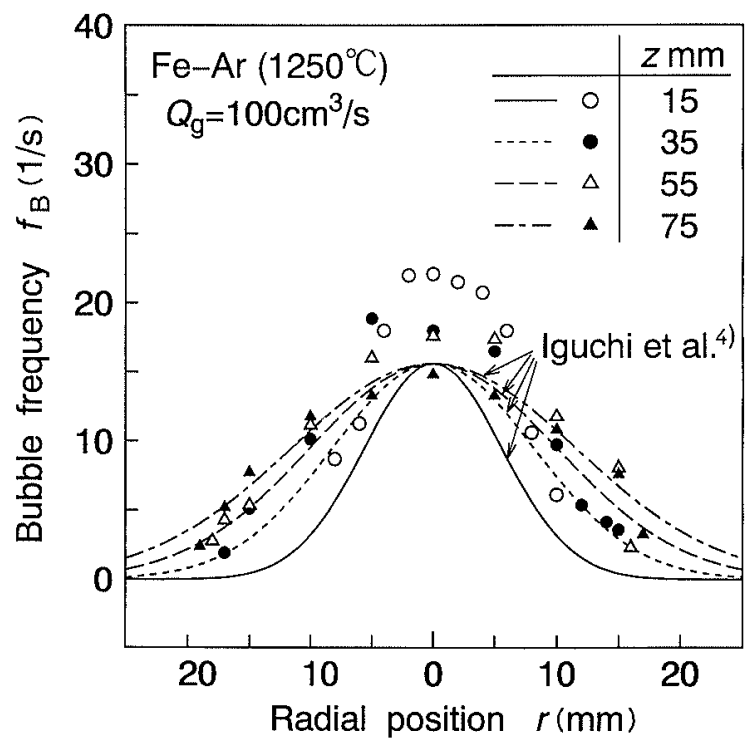

Fig. 11. Radial profiles of bubble frequency $f_{B}$ at different axial positions in the molten iron bath with bottom blowing $\left(1250^{\circ} \mathrm{C}\right)$.

up $\alpha$ at four representative axial positions $(z=15,35,55$, $75 \mathrm{~mm}$ ) for the Ar gas flow rate $Q_{g}=100 \mathrm{~cm}^{3} / \mathrm{s}$, where $r$ is the horizontal distance from the nozzle centerline. The measured values of $\alpha(O)$ obtained in the radial positions close to the centerline of the bath was nearly $60 \%$ at $z=15 \mathrm{~mm}$, and the half-value radius of $\alpha$ was about $7 \mathrm{~mm}$. As $z$ increased and approached the bath surface, the measured values of $\alpha$ abruptly decreased near the centerline of the bath. On the other hand, the half-value radius of $\alpha$ became large and, for example, was about $14 \mathrm{~mm}$ at $z=75 \mathrm{~mm}$. Although the present gas flow rate of $Q_{g}=100 \mathrm{~cm}^{3} / \mathrm{s}$ was approximately $1 / 9$-th as small as employed by Kawakami et al. ${ }^{9)}\left(Q_{g}=860 \mathrm{~cm}^{3} / \mathrm{s}\right)$, the present measured values of $\alpha$ on the bath centerline were much larger than those measured by them. For example, the present measured value of $\alpha$ on the bath centerline was about $20 \%$ at $z=55 \mathrm{~mm}$, while the value measured by Kawakami et al. was about $4 \%$ at $z=50 \mathrm{~mm}$. Agreement between the measured values and the empirical correlation of the present authors was very good in the axial region of $\alpha \leqq 50 \%$, i.e., for $z \geqq 35 \mathrm{~mm}$.

Figure 11 plots the radial distributions of the bubble frequency $f_{B}$. As $z$ increased, the measured values of $f_{B}$ obtained near the centerline of the bath became a little smaller. The difference between the measured values and the empirical correlation is significant near the nozzle exit but it is negligible for $z \geqq 55 \mathrm{~mm}$.

As mentioned above, the mean bubble diameter $\bar{d}_{B}$ is about $15 \mathrm{~mm}$, and hence the axial position of $z=15 \mathrm{~mm}$ is located near the edge of the bubble formation region. Assuming that bubbles are spherical in shape, have the same diameter, and rise straightly in the axial direction, the bubble frequency $f_{B}$ at $z=15 \mathrm{~mm}$ would not change in the radial direction. But the experimental results show that $f_{B}$ decreases clearly in the radial direction. The reason why $f_{B}$ has a radial profile at $z=15 \mathrm{~mm}$ can be explained as follows. Bubbles formed at the nozzle exit does not have the same size ${ }^{8)}$ and they are not spherical in shape. In addition, bubbles are not axisymetrical with

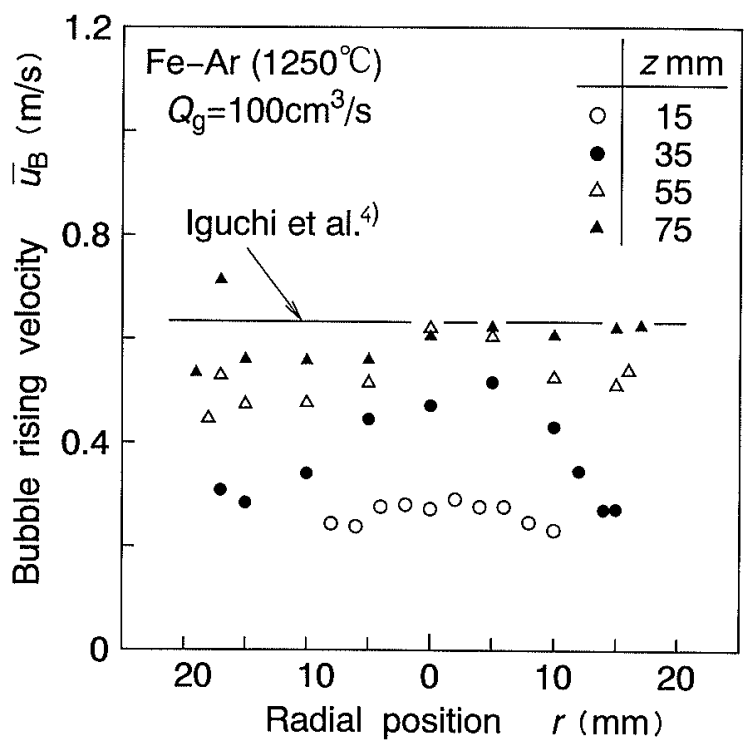

Fig. 12. Radial profiles of mean bubble rising velocity $\bar{u}_{B}$ at different axial positions in the molten iron bath with bottom blowing $\left(1250^{\circ} \mathrm{C}\right)$.

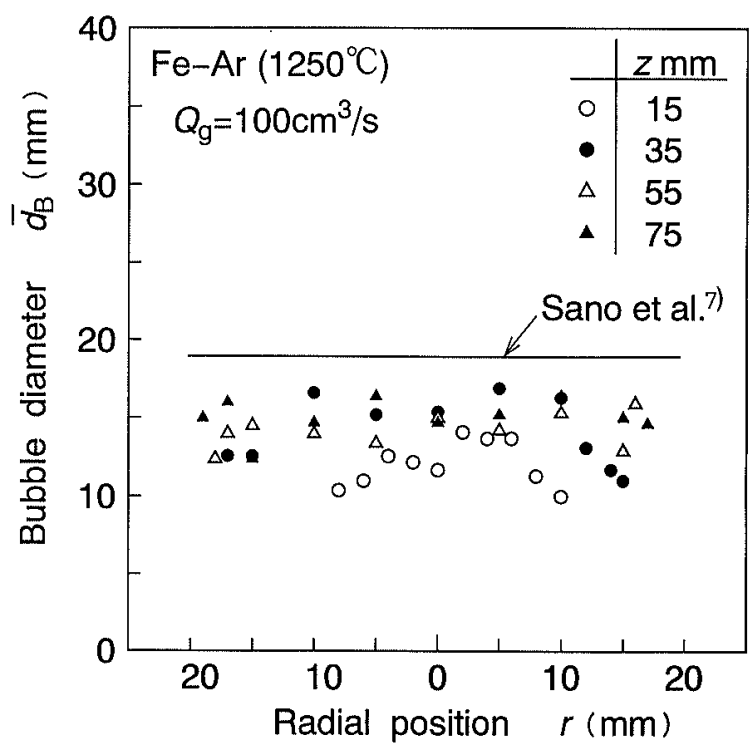

Fig. 13. Radial profiles of mean bubble diameter $\vec{d}_{B}$ at different axial positions in the molten iron bath with bottom blowing $\left(1250^{\circ} \mathrm{C}\right)$.

respect to the nozzle axis and depart from the nozzle while slightly oscillating in the radial direction.

The radial distributions of the mean bubble rising velocity $\bar{u}_{B}$ at the four axial positions are shown in Fig. 12. Change in the measured value of $\bar{u}_{B}$ in the radial direction was very small at each axial position except $z=35 \mathrm{~mm}$. The measured value of $\bar{u}_{B}$ increased as $z$ increased from $z=15 \mathrm{~mm}$ and almost approached the predicted value ${ }^{4)}$ at $z=75 \mathrm{~mm}$.

The radial distributions of the mean bubble diameter $\bar{d}_{B}$ plotted in Fig. 13 indicate that $\bar{d}_{B}$ is almost uniform in the radial direction at axial positions except $z=15 \mathrm{~mm}$. The measured values were smaller than the predicted value of Sano et al. ${ }^{7)}$ everywhere in the bath.

If each bubble is spherical in shape and rises straightly in the axial direction, the bubble chord length $\bar{L}_{B}$ measured using a very fine electrode needle would become 
Table 1. Comparison between injected Ar flow rate $Q_{g, \text { in }}$ and calculated one $Q_{g, c a l}$ from measured $\alpha$ and $\bar{u}_{B, c l}$ values in molten iron bath at $1250^{\circ} \mathrm{C}$.

\begin{tabular}{c|cc|cc}
\hline & $\begin{array}{c}Q_{g, \text { in }} \\
\left(\mathrm{cm}^{3} / \mathrm{s}\right)\end{array}$ & $\begin{array}{c}Q_{g, \text { cal }} \\
\left(\mathrm{cm}^{3} / \mathrm{s}\right)\end{array}$ & $\begin{array}{c}Q_{g, \text { in }} \\
\left(\mathrm{cm}^{3} / \mathrm{s}\right)\end{array}$ & $\begin{array}{c}Q_{g, \text { cal }} \\
\left(\mathrm{cm}^{3} / \mathrm{s}\right)\end{array}$ \\
\hline$z=15 \mathrm{~mm}$ & 50 & 22.2 & 100 & 28.7 \\
$z=35 \mathrm{~mm}$ & 50 & 61.3 & 100 & 77.1 \\
$z=55 \mathrm{~mm}$ & 50 & 65.3 & 100 & 90.2 \\
$z=75 \mathrm{~mm}$ & 50 & 59.7 & 100 & 77.8 \\
\hline
\end{tabular}

gradually small as the radial measurement position departs from the bath centerline. As a result, the radial distribution of $\bar{d}_{B}$ would clearly changes in the radial direction. The fact that the radial distributions of $\bar{d}_{B}$ at $z=55$ and $75 \mathrm{~mm}$ are almost uniform might be caused mainly because bubbles rise in the bath along zig-zag paths.

\section{Comparison between the Injected Gas Flow Rate $\boldsymbol{Q}_{g \text {, in }}$ and the Calculated Gas Flow Rate $Q_{g, c a l}$ from Measured Values of Gas Holdup and Bubble Rising Velocity}

Table 1 shows comparisons between the Ar gas flow rate $Q_{g, \text { in }}$ injected through a single-hole nozzle and the calculated one $Q_{g, c a l}\left(=\int_{0}^{\infty} 2 \pi r \cdot \alpha d r \cdot \bar{u}_{B, c l}\right)$, where the measured values are substituted for $\alpha$ and $\bar{u}_{B, c l}$. Since $\bar{u}_{B}$ remained unchanged in the radial direction, its centerline value $\bar{u}_{B, c l}$ was used for simplicity. In spite of very short measurement time, the calculated value $Q_{g, \text { cal }}$ at every axial position except for $z=15 \mathrm{~mm}$ agreed satisfactorily with the injected value $Q_{g, \text { in }}$ for each Ar gas flow rate. Even for aqueous systems, the degree of agreement was almost the same as observed here. At $z=15 \mathrm{~mm}$, on the other hand, $Q_{g, c a l}$ was much smaller than $Q_{g, \text { in }}$. As this axial position is located near the edge of the bubble formation region, the measured bubble rising velocity does not represent the real bubble rising velocity but a some mixture of the rising velocity and the expanding velocity of the bubble surface. This is the main reason for the significant difference between $Q_{g, \text { in }}$ and $Q_{g, c a l}$ at $z=15 \mathrm{~mm}$

\section{Conclusions}

We developed a new electro-resistivity probe being able to continuously measure bubble characteristics in a molten iron bath at $1250^{\circ} \mathrm{C}$, which was agitated by $\mathrm{Ar}$ gas injection, over two hours. Measurements were made for the molten iron bath at $1250^{\circ} \mathrm{C}$, and the results were summarized as follows:

(1) The axial and radial distributions of gas holdup $\alpha$, bubble frequency $f_{B}$, mean bubble rising velocity $\bar{u}_{B}$ and mean bubble diameter $\bar{d}_{B}$ were measured in the molten iron bath at $1250^{\circ} \mathrm{C}$ for two Ar gas flow rates: $Q_{g}=50 \mathrm{~cm}^{3} / \mathrm{s}$ and $Q_{g}=100 \mathrm{~cm}^{3} / \mathrm{s}$. The radial distributions of $\alpha$ and $f_{B}$ followed the Gaussian distribution, while $\bar{u}_{B}$ and $\bar{d}_{B}$ almost unchanged in the radial direction.

(2) Empirical correlations ${ }^{4}$ of $\alpha, f_{\mathrm{B}}$ and $\bar{u}_{B}$ derived by the present authors based upon cold model experiments could reasonably approximate their respective measured values located in the region far from the nozzle exit. Th: present experimental results differed significä̈íly from those by Kawakami et al. ${ }^{\text {9) }}$

(3) The present measured values of mean bubble diameter $\bar{d}_{B}$ were smaller than predicted values by Sano et $a{ }^{7)}$ and Irons et al. ${ }^{8)}$

\section{Acknowledgment}

The authors wish to express their thanks to associate Professor Iwao Katayama of Osaka University for his fruitful suggestions.

\section{REFERENCES}

1) L. Davidson and E. H. Amick, Jr.: AIChE J., 2 (1956), 337.

2) A. H. Castillejos and J. K. Brimacombe: Metall. Trans. $B, 20$ (1989), 595

3) M. Iguchi, H. Kawabata, T. Iwasaki, K. Nozawa and Z. Morita: Tetsu-to-Hagané, 76 (1990), 840; ISIJ Int., 31 (1991), 952.

4) M. Iguchi, Y. Demoto, N. Sugawara and Z. Morita: Tetsuto-Hagané, 78 (1992), 407; ISIJ Int., 32 (1992), 998.

5) Y. K. Xie, S. Orsten and Oeters: Proc. IISC, 1 (1990), 421

6) M. Sano, K. Mori and T. Sato: Tetsu-to-Hagané, 63 (1977), 2308.

7) M. Sano and K. Mori: Tetsu-to-Hagané, 60 (1974), 348.

8) G. A. Irons and R. I. L. Guthrie: Metall. Trans. B, 9 (1978), 101.

9) M. Kawakami, S. Hosono, K. Takahashi and K. Itoh: Tetsuto-Hagané, 78 (1992), 267.

10) W. D. Kingery, H. K. Bowen and D. R. Uhlmann: Introduction to Ceramics (Second Ed.), trans. by K. Komatsu, T. Sata, Y. Moriyoshi, K. Kitazawa and K. Uematsu, Uchida-Rokakuho Book Co., Ltd., Tokyo, (1983), 871.

11) Y.Shiraki: Fine Ceramics, Gihodo Book Co., Ltd., Tokyo, (1976), 409.

12) Oxidized Ceramics, Nikkato Co., Ltd., Osaka, (1989), 12.

(Originally published in Tetsu-to-Hagané, 80 (1994), 365, in Japanese) 